\title{
Extraction and Recovery of Uranium (VI) from Sulfate Leach Liquor of Gebel Gattar Granites Eastern Desert, Egypt using Di-octylamine
}

\author{
Hassan S. El-Gendy
}

Nuclear Materials Authority, P.O. Box 530 El Maadi, Cairo, Egypt Received: 30 March 2020 / Accepted 10 June 2020 / Publication date: 20 June 2020

\begin{abstract}
A uranyl sulfate leach liquor of Gebel Gattar sample deposits ore was subjected to uranium extraction using the liquid- liquid technique. Uranium was effectively extracted from sulfate leach liquor by $0.2 \mathrm{M}$ di-octylamine (DOA) dissolved in kerosene as a diluent. The extraction efficiency was markedly enhanced as the concentration of DOA increases from 0.05 to $0.5 \mathrm{M}$. The relevant factors controlling the extraction process of uranium using di-2-octyle amine were studied. These factors include the effect of DOA concentration, contact time, $\mathrm{pH}$ value and phase ratio $(\mathrm{A} / \mathrm{O}) \mathrm{v} / \mathrm{v}$. Under the optimum conditions, more than $91 \%$ of uranium was extracted by $0.2 \mathrm{M} \mathrm{DOA}$, at contact time $30 \mathrm{~min}$, phase ratio (VA/VO) $1 / 1$ at $\mathrm{pH} 2$ and at room temperature. The feasibility of using the DOA for preconcentration-separation of uranium was assessed by stripping studies. The loaded uranium onto DOA has been stripped by $89 \%$ using $1.5 \mathrm{M} \mathrm{HNO}_{3}$ as an efficient stripping agent at 15 min contact time, and phase ratio $(\mathrm{O} / \mathrm{A}) 1 / 1$.
\end{abstract}

Keywords: Uranium extraction, Di-octylamine, Gebel Gattar

\section{Introduction}

Over several past years, there were different tools adopted for the separation and recovery of actinides from there ores including precipitation, co-precipitation, ion exchange and solvent extraction processes (SEPP, 2004 and Ansari et al., 2011). Solvent, or liquid-liquid, extraction was one of the most important separation processes in hydrometallurgy. Liquid-liquid extraction (LLE) is a process in which a particular solute is removed from a liquid phase (feed phase) by another liquid phase (solvent or extractant phase). The organic medium usually contains lipophilic complexing agents that promote distribution of the analyte into the organic phase by the formation of lipophilic complexes or ion pairs (Khopkar, 2009 and Xie et al., 2014), the diluent should not be too volatile specially if the equilibrium takes long time (Atanassova et al., 2016). Shakir (1980) investigated the extraction of uranium using neotridecanohydroxamic acid (HX-70), in which depends on the diluent used. The uranium extraction coefficient increase with decreasing phosphate and hydrogen ion and appreciable only at $\mathrm{pH}$ values $>2$. A study was performed for the extraction of $\mathrm{U}(\mathrm{VI})$ and $\mathrm{Th}(\mathrm{IV})$ from nitric acid medium employing microporous hollow fiber membrane with several monoamide extractants, and the results obtained were compared with those obtained with TBP (Ansari et al., 2016), different factors affecting the extraction rate was examined as well as flow rate and feed metal ion concentration. A study of the synergistic effect of different neutral donors extractants like tri-butyl phosphate (TBP), tri-octyl phosphine oxide (TOPO), tri-phenyl phosphine oxide (TPPO) and dimethyl sulphoxide (DMSO) on the extraction of uranium using tri-isooctyl amine dissolved in $\mathrm{CCl}_{4}$ was investigated (Biswas and Basu, 1997). Chagnes et al. (2009) proposed a way to delay the degradation of tri-octyl amine in kerosene through the extraction and recovery of uranium from sulphate media as well as enhancement the extraction and recovery efficiency without addition further new extractant by replacement of classical counter-current flow-sheets with a unique extraction-stripping loop in unusual combined flow-sheets with two or more independent extraction-stripping loops and with one or more feed inlets. Seven different aminophosphonates (AmPs) with alkyl, cyclohexyl and phenyl substitution were synthesized and characterized with various spectroscopic techniques, extraction behavior of these synthesized AmPs were performed with some actinides [U(VI), Th(IV), and $\mathrm{Am}(\mathrm{III})]$ and also studied their acid uptake as a function of nitric acid concentration (Das et al., 2018). An experiment was carried out to investigate the uranyl ion transport from $\mathrm{HCl}$ media using 0.2 micron PTFE filters as the membrane support and 30\% alamine 336 in toluene as a carrier in which

Corresponding Author: Hassan S. El-Gendy, Nuclear Materials Authority, P.O. Box 530 El Maadi, Cairo, Egypt. E-mail: elgendy_nma@yahoo.com 
distilled water was used as the stripant (Lakshmi et al., 2004). Loon Ang et al. (2017) performed ion exchange resins with different functional groups to separate uranium(VI) and thorium(IV) from rare earth elements REE(III) in sulfuric acid medium with different concentration, these resins were comprised strong- and weak-base anion exchange resins, and strong- and weak-acid cation exchange resins. Chelating resins with different functional groups as bis-pi-colylamine resin, aminophosphonic resins, iminodiacetic resins, and solvent-impregnated resins were examined for the separation of uranium, and thorium from rare earth elements in aqueous sulfate media (Loon Ang et al., 2018). Cyanex extractants were used to develop $\mathrm{UO}_{2}{ }^{2+}$ polymer membrane electrode. The effect of membrane composition, $\mathrm{pH}$ and foreign cations were studied (Badr, 2014). Hadadian et al. (2016) investigated a dispersive solvent extraction technique for optimal conditions of uranium (VI) separation from aqueous leach liquor solution containing uranium(VI), thorium(IV), iron(III), $\mathrm{Cl}^{-}$, $\mathrm{SO}_{4}^{-}$, etc . A transport of uranyl ion across a supported liquid membrane made from Aliquat 336 in Chloromethylene $(\mathrm{CHCl})$ as the carrier was performed from an aqueous feed containing hydrochloric acid (Mohapatra et al., 2006). The adsorption of uranium(VI) originated from El-Sebaiya phosphate ore using amine impregnated cellulous (AIC) was investigated. The impregnation process was carried out by copolymerization between pretreated cellulose and a mixture of (tri-ethyl amine and epichorohydrine), the optimum conditions were studied in which the maximum uptake of uranium was found to be $56.5 \mathrm{mgU} / \mathrm{g}$ AIC (Orabi et al., 2015.). Toker et al. (1998) performed the sorption and desorption of uranium (IV) from dilute uranyl sulfate using trioctylamine impregnated polyurethane foam, different factors were studied for the optimum conditions achieved as uranium concentration, ratio of solution volume to foam weight $\left(\mathrm{ml} \mathrm{g}^{-1}\right), \mathrm{pH}$, time and temperature. The extraction of uranium (IV) from different media as nitrate, sulfate and chloride with trioctylamine in benzene was investigated. The calculated equilibrium constants are $46.5,89.4$ and $4.2 \times 10^{4}$ for uranyl nitrate, chloride and sulfate respectively (Comor et al., 2001). Extraction and recovery of uranium (IV) from monazite using trioctylamine was investigated and several factors were examined to obtain the optimum conditions (Elgendy, 2014).

Trioctylmine impregnated activated carbon was used for the extraction of uranium(VI) from sulfate media in which different parameters affect on the extraction as contact time, $\mathrm{pH}$, initial uranium concentration and temperature were studied (Ahmed et al., 2013). Yousef and Saleh, (2014) studied the removal of uranium and thorium from flood water at Abu Rusheid area, south eastern desert, Egypt using trioctylamine in kerosene. El-Sella south eastern desert, Egypt sample deposits ore was subjected to uranium extraction using the liquid-liquid technique from sulfate leach liquor by 10 $\%$ tri-n-octylamine dissolved in benzene as a diluent (Daher et al., 2015). The recovery of uranium (VI) from heap leach liquor with trioctylamine in kerosene was carried out by Goldenberg and Abbruzzese (Goldenberg and Abbruzzese, 1983). Trioctylamine in xylene was used for the extraction and recovery of uranium(VI) from hydrophilic phosphoric acid residue under several factors and found that, the maximum extraction and stripping efficiency was observed as $92 \%$ (Guirgui et al., 2013). The extraction of uranium (VI) in sulfuric acid medium was performed using trioctylamine in benzene (Južniç and Fedina, 1974), while the extraction of uranium (VI) from hydrochloric acid media with trioctylamine dissolved in benzene was investigated (Kojima et al., 1969). Daher et al. (2014) reported the extraction and recovery of uranium(VI) from uranyl sulfate leach liquor of a technological sample of salcrete deposits of Gabal Qatrani ore by a liquid-liquid extraction technique using $10 \%$ trioctylamine in xylene as a diluent, factors affecting the extraction and stripping efficiency were studied. The extraction of uranium(VI) from sulfate and nitrate media using Alamine 300 and di-n-octyl amine solvents (DOA), influence of the acid, carrier and U(VI) concentrations on the removal efficiency of $\mathrm{U}(\mathrm{VI})$ has been subjected (Senol, 2014). The percentage extraction U(VI), $\mathrm{Mo}(\mathrm{VI}), \mathrm{Zr}(\mathrm{IV})$ and $\mathrm{Sr}(\mathrm{II})$ from 1-6 M nitric acid by trioctylamine (TOA) and its radiolytic degradation products dioctylamine (DOA) and primary octylamine (POA) in xylene have been performed (Al-Ani and Masoud, 1982).

This paper was investigated to extract and recovery of uranium (VI) from sulfate leach liquor of Gebel Gattar using DOA dissolved in kerosene. The marketable product of yellow cake has been performed. 


\section{Experimental}

\section{Materials}

All chemicals used were of analytical grade and were used without further purifications, hydrochloric acid, sulfuric acid, nitric acid, acetic acid, sodium chloride, sodium sulfate, sodium hydroxide, sodium carbonate and uranyl acetate (Fluka, POCH S.A. Poland and Scharlau Chemie. S.A. Spain). Bi-distilled water was used for preparing standard solutions and glassware washing. Dioctyl amine (DOA) Merk, Germany, dissolved in odorless kerosene (Misr Petrol. CO., Egypt) was used as a good and selective extractant for liquid-liquid extraction of uranium(VI) from Gebel Gattar. Slit width was fixed at $2 \mathrm{~nm}$ and all experiments were carried out in $1 \mathrm{~cm}$ quartz cell at laboratory temperature for the determination of U(VI) using arsenazo III.

Gebel Gattar sample leach liquor has been prepared under the optimum leaching conditions including sulfuric acid (10 g/l),1/4 solid/liquid ratio at room temperature for $4 \mathrm{~h}$ leaching time (Abd El-Magied et al., 2018). The chemical composition of the concerning leach liquor has been tabulated at table (1).

Table 1: Chemical composition of Gebel Gattar leach liquor

\begin{tabular}{cc}
\hline Component & Concentration $\mathbf{g} / \mathbf{L}$ \\
\hline $\mathbf{F e}_{2} \mathbf{O}_{3}$ & 0.365 \\
$\mathrm{SO}_{4}^{--}$ & 1.87 \\
$\mathbf{U}$ & 0.45 \\
$\mathbf{M O}$ & 0.08 \\
$\mathbf{p H}$ & 1.8 \\
\hline
\end{tabular}

\section{Experimental procedures for liquid-liquid extraction of U(VI) using DOA}

In $50 \mathrm{ml}$ volume separating funnel, $10 \mathrm{ml}$ of clean leach liquor containing uranium(VI) was mixed with $10 \mathrm{ml}$ of $0.2 \mathrm{M}$ DOA dissolved in kerosene as a diluent with aqueous/organic phase ratio of $1: 1$. The whole solution was shaken at room temperature for an equilibration time of 30 minutes at $\mathrm{pH}$ 2. After 30 seconds settling time, the separation of the two phases from each other completely done. Then the loaded organic phase was scrubbed using $10 \mathrm{ml}$ bi-distilled water to ensure the removing of co-extracted impurities.

\section{Uranium stripping}

Uranium was stripped from the obtained loaded amine (DOA) solvent using dilute nitric acid as stripping agents. Uranium concentration was determined in the aqueous phase after each contact, and the corresponding concentration in the organic phase was calculated by difference. The stripping factors studied involved nitric acid concentration, contact time and $\mathrm{O} / \mathrm{A}$ phase ratio.

\section{Analytical analysis of uranium}

$\mathrm{U}(\mathrm{VI})$ were determined spectrophotometrically in all aqueous samples using a double beam spectrophotometer of high resolution power (UNICAM UV/Vis spectrophotometer model UV2-100, England).

\section{Results and Discussion}

\section{Factors affecting the extraction process}

\section{Effect of different concentrations of DOA on percent extraction}

Different concentrations of DOA were used to study its effect on the extraction percent. In 50 $\mathrm{ml}$ volumetric flask, $10 \mathrm{ml}$ of DOA dissolved in kerosene with concentrations ranging from 0.05 $0.5 \mathrm{M}$ and the solution was shaken for 30 minutes at room temperature to attain equilibrium state. From the obtained results in figure (1), it was found that percent extraction of U(VI) was increased gradually with increasing DOA concentration from 0.05 to $0.2 \mathrm{M}$. Over $0.2 \mathrm{M}$ DOA, the percent of extraction was decreased gradually, in which the extraction efficiency over $0.2 \mathrm{M}$ DOA almost the same, so that $0.2 \mathrm{M}$ DOA dissolved in kerosene was the best concentration used in liquid-liquid 
extraction of $\mathrm{U}(\mathrm{VI})$, probably due to the increased in viscosity of extractant (DOA) that causes a decrease in the mass transfer of $\mathrm{U}(\mathrm{VI})$ from aqueous to organic phase which was the main cause for decreasing the extraction efficiency.

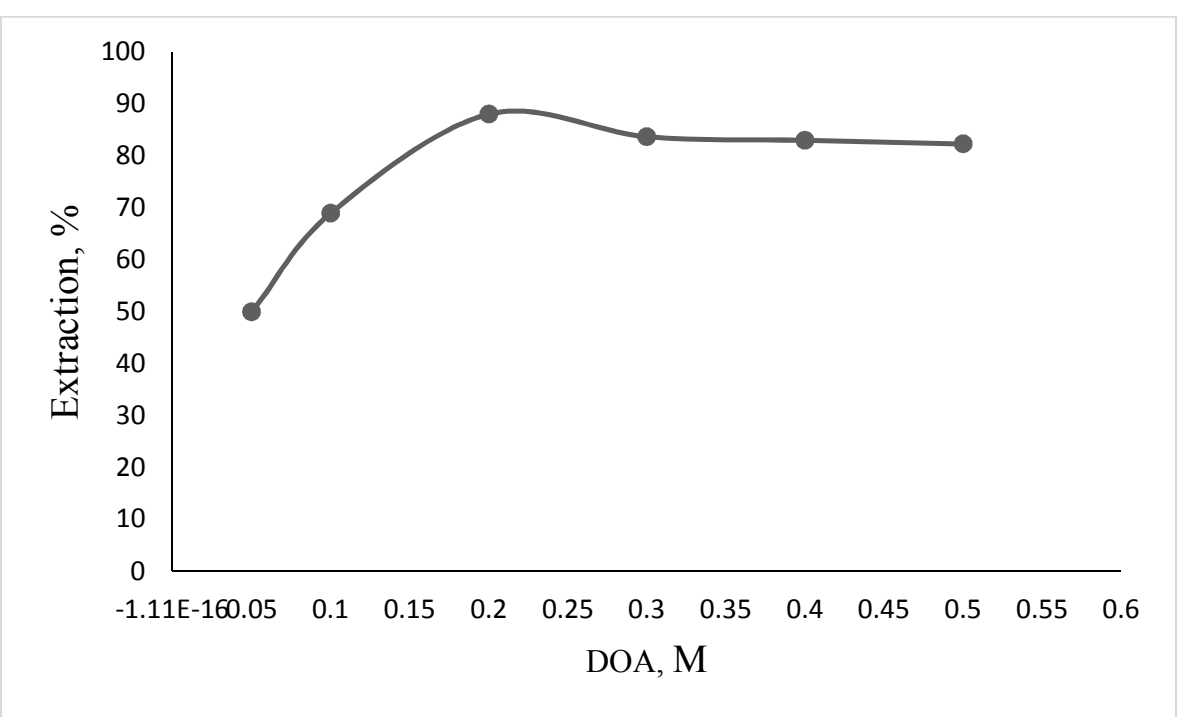

Fig. 1: Effect of DOA concentration (M) upon uranium extraction efficiency.

\section{Effect of shaking time upon uranium extraction}

The effect of the shaking time upon uranium extraction efficiency was studied by performing a series of extraction experiments using different shaking times ranging from 5 to $60 \mathrm{~min}$. The other parameters were kept constant at 0.2M DOA in kerosene, aqueous/organic phase ratio 1:1 and pH 1.7 at room temperature. It was observed that the extraction percent was gradually increased from 5 to 30 minutes and then it was slightly decreased over this time, probably due to the entrainment of some organic phase droplet into aqueous phase, which cause a slight decrease in the extractive power of extractant, so that 30 minutes was chosen as the best equilibration time for the extraction of U(VI), Figure (2). This was a short time for the highest extraction which confirms that the amine DOA was kinetically faster in extraction of $\mathrm{U}(\mathrm{VI})$.

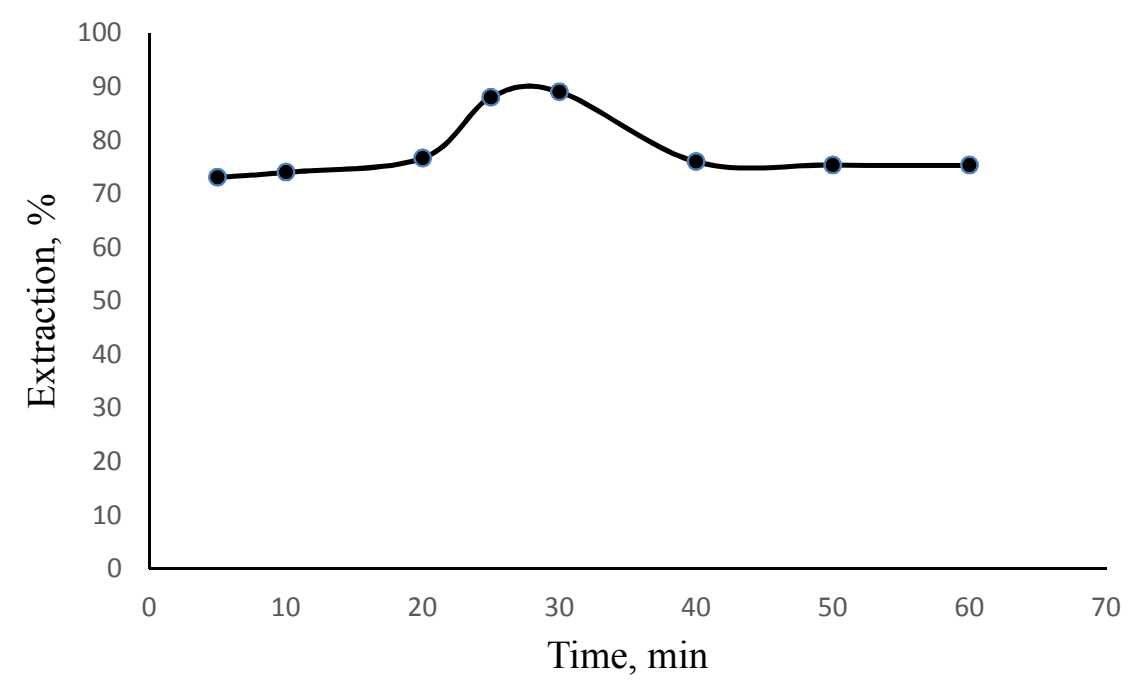

Fig. 2: Effect of contact time on uranium extraction efficiency. 


\section{Effect of diluent on uranium extraction}

The effect of diulent upon the extraction of uranium(VI) is a very important factor, so a series of experiments were performed to study the effect of different diluents on the percent extraction of uranium(VI) with fixing other parameters at $0.2 \mathrm{M}$ DOA, aqueous / organic phase ratio at 1:1, 30 minutes contact time, $\mathrm{pH} 1.7$ at room temperature. From figure (3), it was noticed that DOA in different diluents like xylene, chloroform, benzene and kerosene gave an extraction of uranium, but DOA dissolved in kerosene as a diluent was chosen as the best one to obtain the highest percent extraction of uranium(VI).

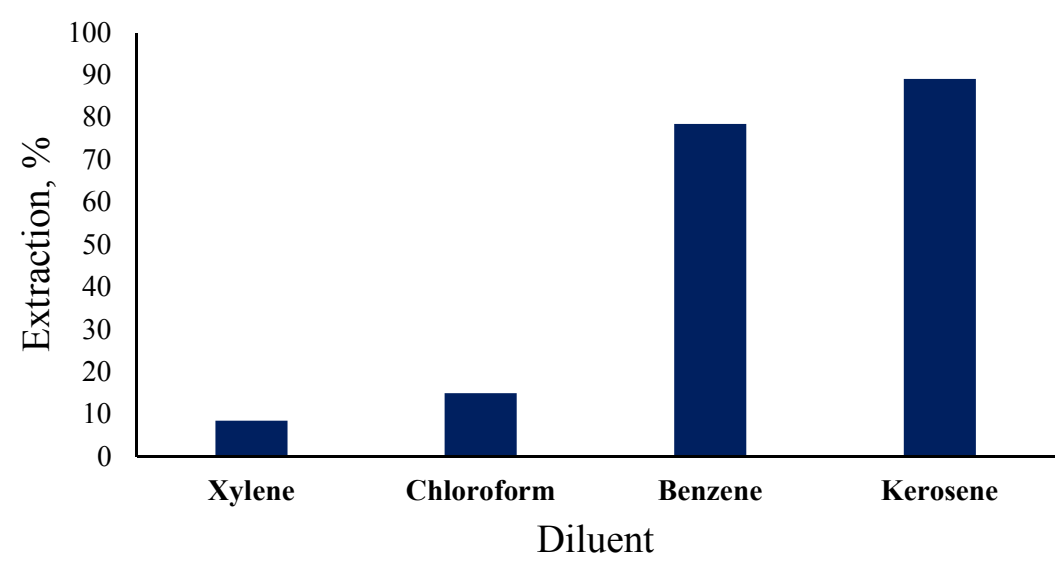

Fig. 3: Effect of diluent on uranium extraction efficiency.

\section{Effect of aqueous/organic phase ratio on uranium extraction}

A series of experiments were investigated to study the effect of aqueous/organic ratio on uranium extraction with kept other parameters at $0.2 \mathrm{M}$ DOA dissolved in kerosene, 30 minutes shacking time, $\mathrm{pH} 1.7$ at room temperature. From the results obtained in figure (4), it was observed that 1:1 aqueous to organic phase ratio was the best one to obtain the best percent extraction.

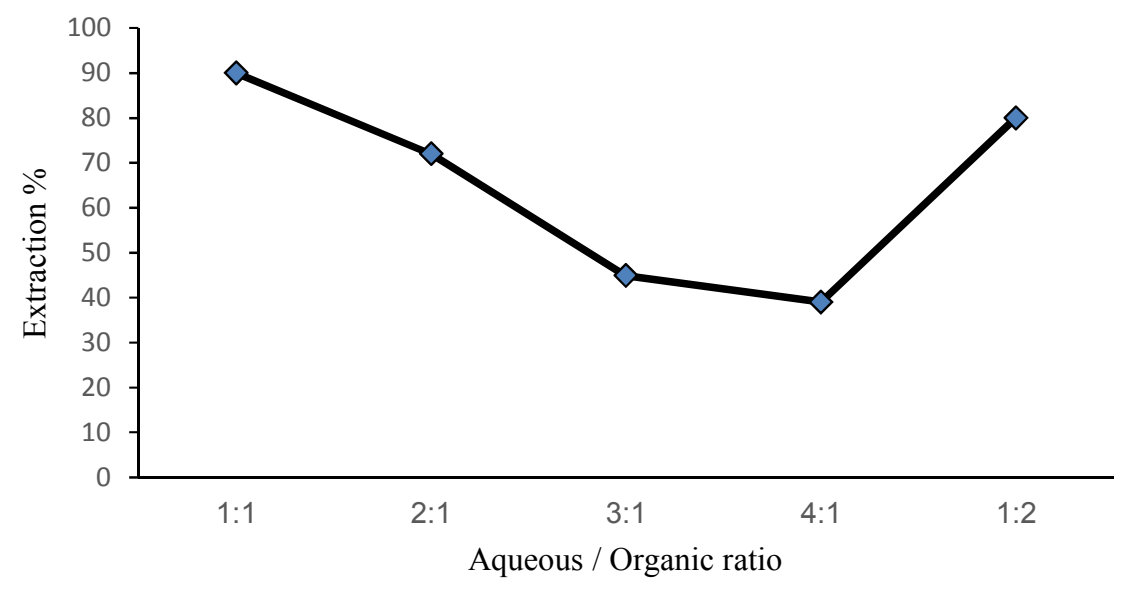

Fig. 4: Effect of aqueous/organic phase ratio on uranium extraction.

\section{Effect of $\mathrm{pH}$ value upon uranium extraction}

The effect of $\mathrm{pH}$ upon the extraction of uranium(VI) is a very important factor, in order to study the effect of $\mathrm{pH}$ value on the percent extraction of uranium(VI) in this present work with $0.2 \mathrm{M} \mathrm{DOA}$, a series of extraction experiments was performed using different $\mathrm{pH}$ values ranging from $0.5-3$ through the liquid-liquid extraction of the $\mathrm{U}(\mathrm{VI})$ was performed with fixing other factors at $0.2 \mathrm{M}$ DOA dissolved in kerosene, 1:1 aqueous/organic phase ratio at 30 minutes and at room temperature. 
The obtained results in figure (5) revealed that the percent of extraction of U(VI) was increased gradually by the increase of $\mathrm{pH}(0.5-3)$, while the best $\mathrm{pH}$ value was observed at $\mathrm{pH} 2$. Over $\mathrm{pH} 2$, the extraction percent was decreased.

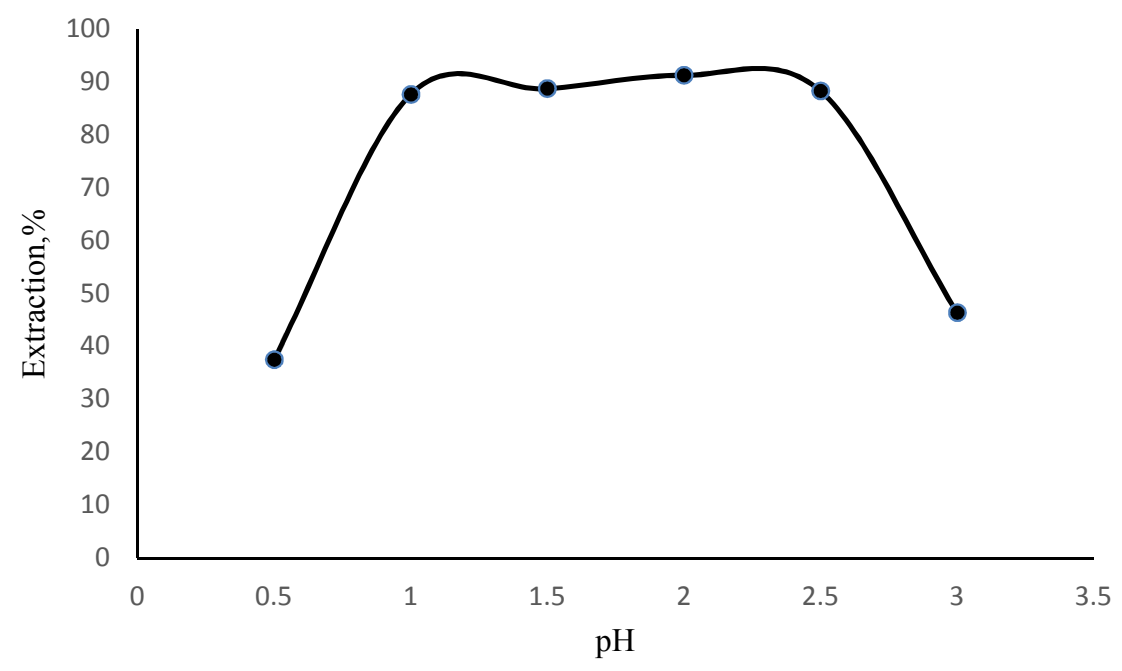

Fig. 5: Effect of $\mathrm{pH}$ value upon uranium extraction efficiency

\section{Effect of Temperature upon uranium extraction}

The effect of temperature upon the extraction efficiency of uranium(VI) was very important, in which a series of experiments were performed to study the effect of temperature on uranium extraction ranging from $22-55 \mathrm{C}^{\circ}$ with kept other parameters fixing at $0.2 \mathrm{M}$ DOA in kerosene, aqueous to organic ratio was $1: 1$ at 30 minutes shaking time and $\mathrm{pH} 2$. From the results obtained in figure (6), it was observed that, the extraction percent was decreased gradually from $22-55 \mathrm{C}^{\mathrm{o}}$, so room temperature was chosen as the best one for the extraction of uranium using DOA in kerosene.

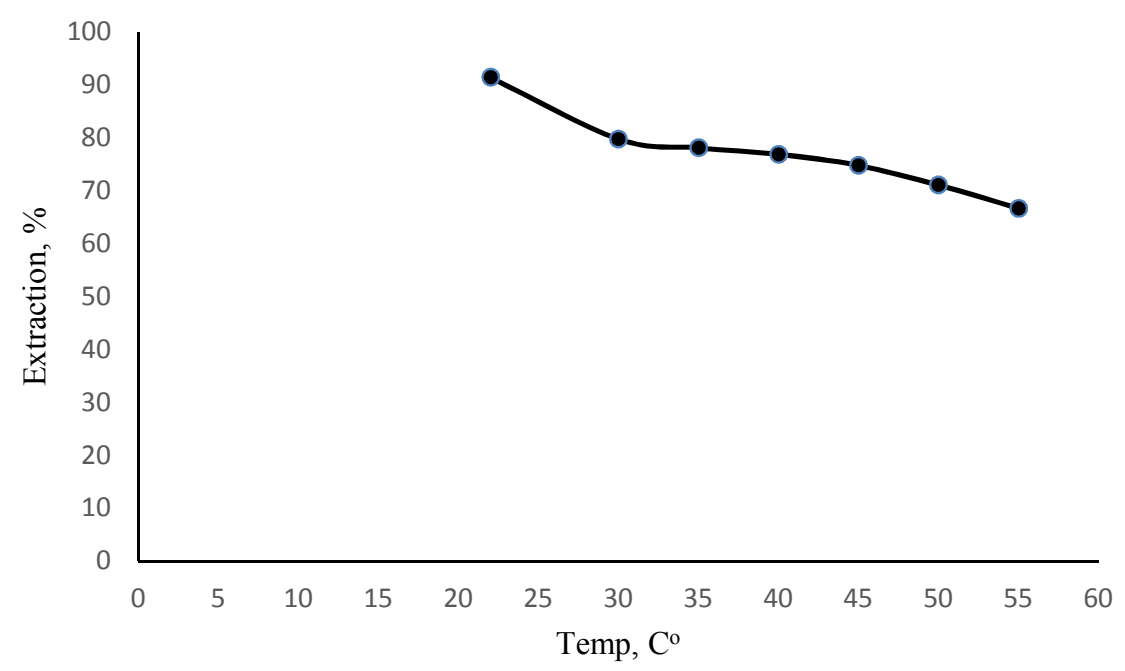

Fig. 6: Effect of Temperature upon uranium extraction efficiency.

\section{Factors affecting the stripping process}

\section{Effect of different stripping agents upon uranium stripping}

Several expierments for re-extraction of uranium (VI) from the prepared loded DOA were investigated using different acidic, neutral and alkaline stripping agents. From the obtained resluts in 
figure (7), it was noted that $\mathrm{HNO}_{3}$ was chosen as the best stripping agent for uranium(VI) reextraction.

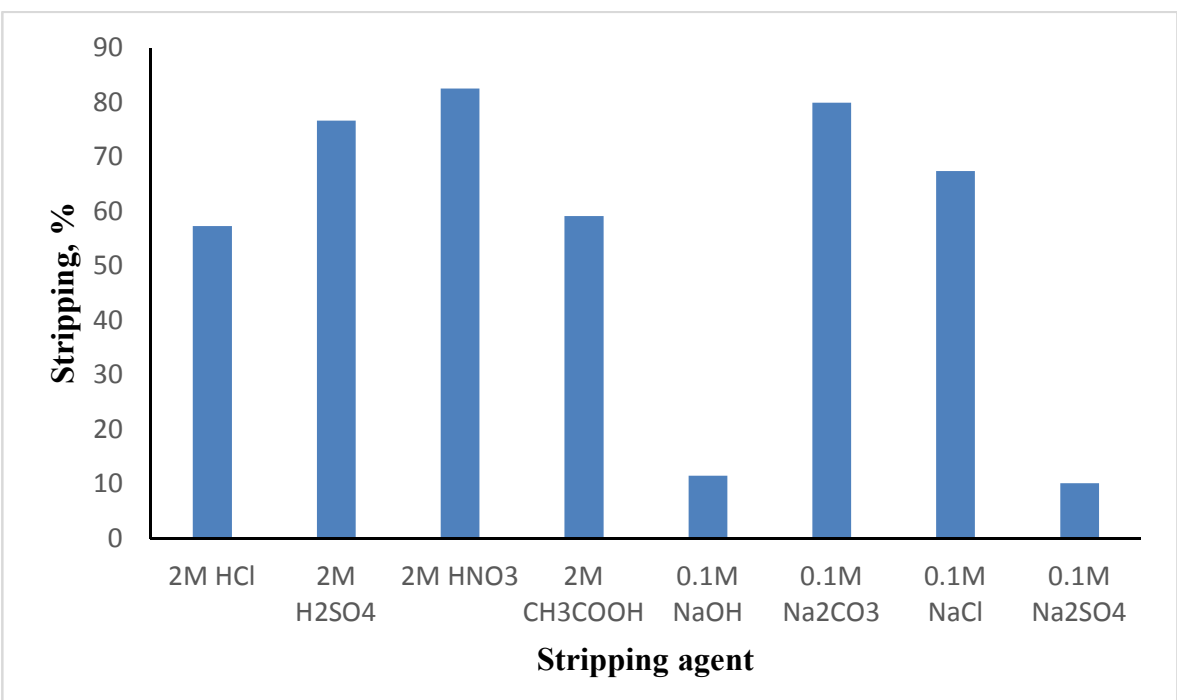

Fig. 7: Effect of different stripping agents upon uranium stripping effeciency.

\section{Effect of $\mathrm{HNO}_{3}$ upon uranium stripping}

A series of stripping experiments were carried out for the stripping of uranium(VI) from the loaded organic DOA using different concentrations of $\mathrm{HNO}_{3}$ ranging from 0.05-3 $\mathrm{M}$ at room temperature, $1: 1(\mathrm{v} / \mathrm{v})$ organic:aqueous phase ratio and 15 minutes shaking time, the results obtained were illustrated in figure (8). From these results, it was noted that, the stripping efficiency was increased from 0.05 into $1.5 \mathrm{M} \mathrm{HNO}_{3}$, over this concentration, the stripping percent was gradually decreased, hence $1.5 \mathrm{M} \mathrm{HNO}_{3}$ was chosen as the optimum concentration for uranium(VI) re-extraction percent.

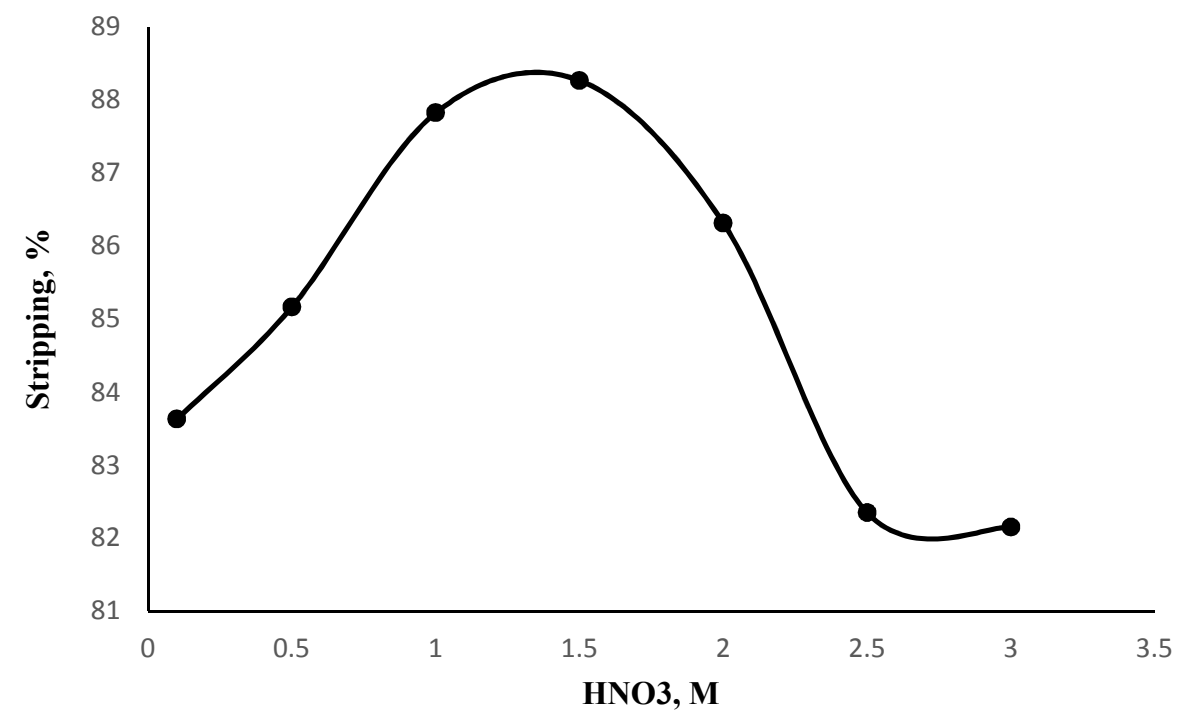

Fig. 8: Effect of $\mathrm{HNO}_{3}$ upon uranium stripping efficiency.

\section{Effect of equilibrium time upon uranium re-extraction percent}

The effect of contact time on the attainment of an equilibrium state had been studied at the time intervals 5 to 30 minutes while the other factors were kept at $1.5 \mathrm{M} \mathrm{HNO}_{3}$ and $1: 1(\mathrm{v} / \mathrm{v})$ organic to 
aqueous phase ratio and at room temperature. The obtained data revealed that contact time of 15 minutes was sufficient for uranium stripping from the loaded DOA solvent, figure (9).

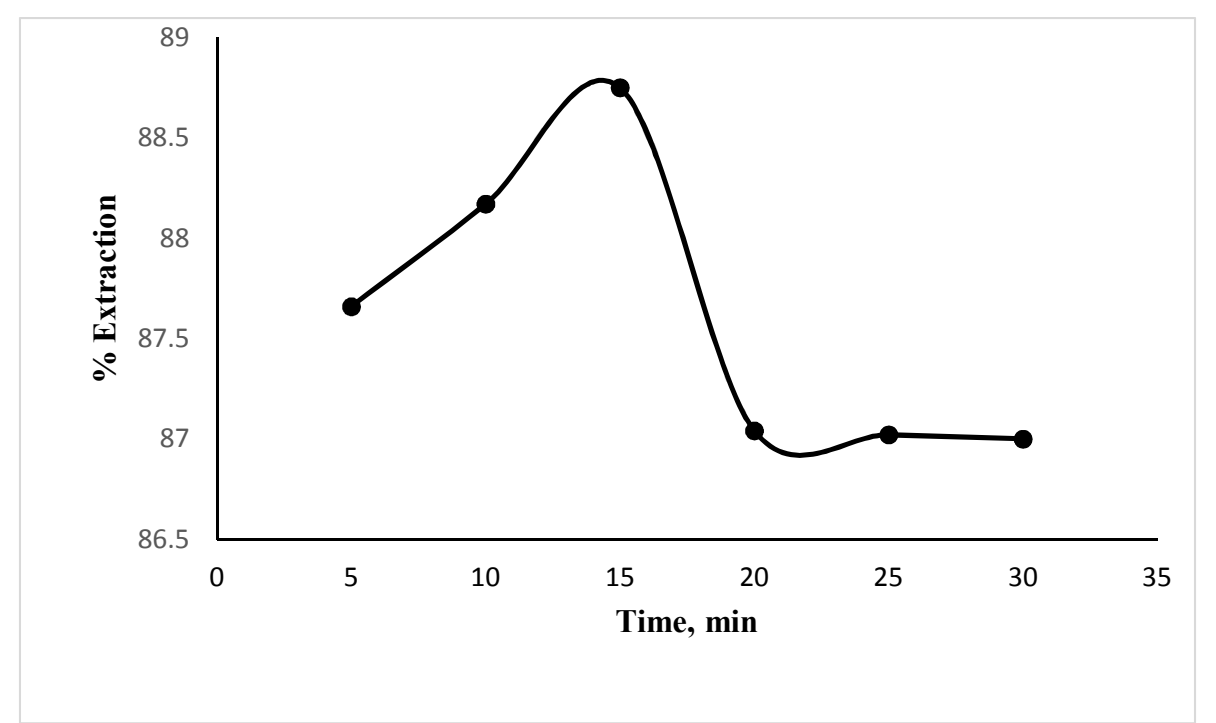

Fig. 9: Effect of contact time upon uranium re-extraction efficiency

\section{Application of the optimum conditions on uranium extraction from Gattar sample}

Before the extraction process, iron should be precipitated from the sulfate leach liquor by adjusting its $\mathrm{pH}$ at 3.5 with $20 \%(\mathrm{w} / \mathrm{v}) \mathrm{NH}_{4} \mathrm{OH}$ whereas the $\mathrm{Fe}(\mathrm{III})$ was precipitated and separated, hence the filtrate obtained included uranium(VI) was examined for uranium extraction and stripping using the above optimum conditions. Using $20 \% \mathrm{NH}_{4} \mathrm{OH}$ the precipitation of yellow cake was done after its drying process at $70 \mathrm{C}^{\circ}$. The latter was then subjected to semi qualitative analysis (EDAX analysis) to confirm the composition of obtained yellow cake, figure (10). Also, the yellow cake subjected to chemical analysis and the uranium in empirical formula (ammonium diuranate) was assay about $68 \%$.

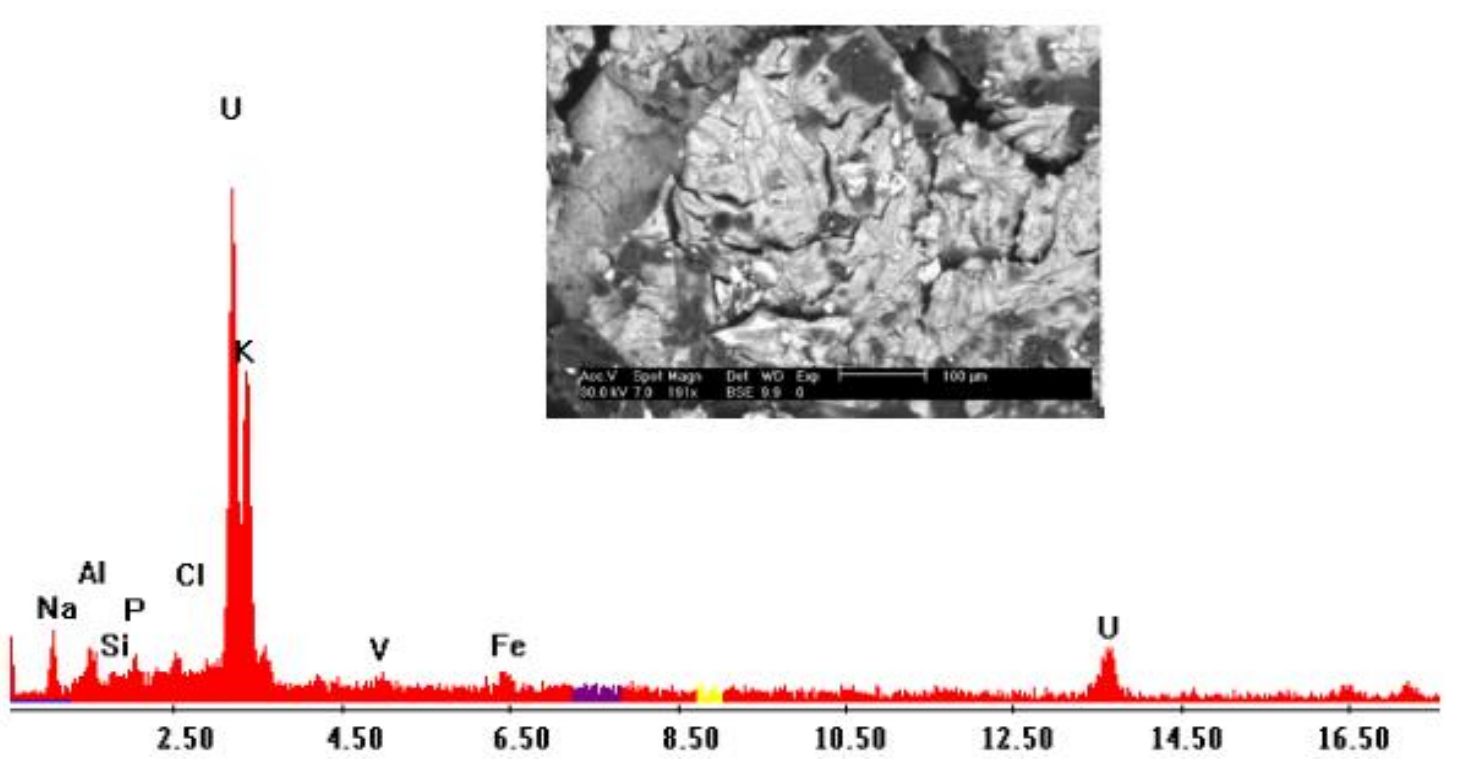

Fig. 10: EDAX of obtained yellow cake (ammonium diuranate ) 


\section{Conclusion}

From the obtained results it was concluded that the separate extraction and recovery of uranium from the prepared leach liquor of Gebel Gattar composite sample, it was applied using di-octyl amine (DOA) for prior uranium extraction. The corresponding relevant extraction and stripping factors had been studied. Accordingly, 0.2M DOA dissolved in kerosene at room temperature, 1:1 A/O phase ratio at $\mathrm{pH}$ value of 2 and 30 minutes shaking time was chosen as the optimum conditions for uranium (VI) extraction in its pregnant sulfate leach liquor, and the optimums conditions for stripping was investigated at $1.5 \mathrm{M} \mathrm{HNO}_{3}$ at $\mathrm{O} / \mathrm{A}$ ratio of $1: 1$ at 15 minutes contact time, finally the EDAX of the precipitated yellow cake was performed.

\section{References}

Abd El-Magied, M.O., A.S. Dhmees, A.M. Abd El-Hamid and E.M. Eldesouky, 2018. Uranium extraction by sulfonated mesoporous silica derived from blast furnace slag, Journal of nuclear materials, 205: 295-304.

Ahmed, S.H., C.M. Sharaby and E.M. El Gammal, 2013. Uranium Extraction from Sulfuric Acid Medium Using Trioctylamine Impregnated Activated Carbon, Hydrometallurgy. doi: 10.1016/j.hydromet.2013.02.003.

Al-Ani, A.M. and F.M. Masoud, 1982. A comparison of the extraction capacity of trioctylamine and its radiolytic products dioctylamine and primary octylamine for the elements U(VI), Mo(VI), $\mathrm{Zr}(\mathrm{IV})$ and Sr(II), Hydrometallurgy, 9:211-214.

Ansari, S.A., P. Pathak, P.K. Mohapatra, V.K. Manchanda, 2011. Sep. Purif. Rev. 40: 43-76.

Ansari, S.A., N. Kumari, D.R. Raut, P. Kandwal, and P.K. Mohapatra, 2016. Comparative dispersionfree solvent extraction of uranium(VI) and thorium(IV) by TBP and dialkyl amides using a hollow fiber contactor, Separation and Purification Technology. doi: http://dx.doi.org/10.1016/j.seppur.2016.01.004.

Atanassova, M., V. Kurteva and I. Dukov, 2016. The interaction of extractants during synergistic solvent extraction of metals. Is it an important reaction, The Royal Society of Chemistry, 6, $81250-81265$.

Badr, I.H.A., W.I. Zidan and Z.F. Akl, 2014. Cyanex based uranyl sensitive polymeric membrane electrodes, Talanta, 118:147-155.

Biswas, S. and S. Basu, 1997. Synergic extraction of uranium(VI) by combination of tri-isooctylamine and neutral donors, journal of radioanalytical and nuclear chemistry, 220(2): 267269.

Chagnes, A., B. Courtaud, J. Thiry and G. Cote, 2009. Computer simulation of flow-sheets for the solvent extraction of uranium: a new route to delay the effect of chemical degradation of the organic phase during uranium recovery from acidic sulfate media, Journal of Chemical Technology and Biotechnology, 841899-1907.

Comor, J., J., Djordjem and M. Petkovic, 2001. Extraction of uranyl nitrate, sulphate and chloride with tri-n-octyl amine (TOA) from aqueous solutions, J. Serb. Chem. Soc., 66(7): 443-449.

Daher, A.M., S. Abdel Wanees, H.M.A. Kellah, A.H. Ali, 2014. Removal of uranium from sulfate leach liquor of salcrete deposits using tri-n-octyl amine, Journal of Radio analytical and Nuclear Chemistry, 299:493-499.

Daher, A.M., M.M. Abu Ali, A.E.M Hussein and A.S El-Sheikh, 2015. Extraction of uranium from el-Sella mineralization south eastern desert, Egypt by tri-Octylamine, Chemical technology, 10(4):136-143.

Das, D., C.V.S. Brahmmananda Rao, N. Sivaraman, A. Sivaramakrishna and K. Vijayakrishna,2018. Synthesis and Extraction behavior of Alkyl and Cyclic Aminophosphonates towards Actinides, Inorganica Chimica Acta. Doi: https://doi.org/10.1016/j.ica.2018.07.002.

Elgendy, H.S., 2014. Equilibrium and kinetics studies on the extraction of some rare earth elements from Egyptian black sand monazaite, Ph.D. Thesis, Faculty of Science, Benha University, Egypt.

Goldenberg, J. F., C. Abbruzzese, 1983. Extraction of uranium from heap leach liquor with tri-noctylamine: equilibrium data and flowsheet calculations, international journal of mineral processing, 10: $241-254$. 
Guirgui, L.A.S., R.M. Elrakaiby, N.I. Filaila, 2013. Recovery of Uranium from Hydrophilic Phosphoric Acid Residue Using Trioctylamine, Journal of Basic and Applied Scientific Research, 3(11):64-70.

Hadadian, M., M. H. Mallah, M.A. Moosavian, J. Safdari and M. Davoudi, 2016. Separation of uranium (VI) using dispersive liquid-liquid extraction from leach liquor, Progress in Nuclear Energy, 90, 212-218.

Južniç, K., S. Fedina, The extraction of uranium(IV) from sulfuric acid by tri-octylamine in benzene, Mikrochimica Acta, 1974, 39 - 44.

Khopkar, S., 2009. Solvent extraction-separation of elements with liquid ion exchangers, New Age Sci. Limited, the control centre, 11A Little Mount Sion, Tunbridge wells, Kent TN1, UK.

Kojima, T., H. Fukutomi and H. Kakihana, 1969. Extraction of Uranium (VI) from Hydrochloric Acid Solution by Tri-n octylamine in Benzene, Journal of Nuclear Science and Technology, 6(2): 8189.

Lakshmi, D.S., P.K. Mohapatra, D. Mohan, V.K. Manchanda, 2004. Uranium transport using a PTFE flat-sheet membrane containing alamine 336 in toluene as the carrier, desalination 163, 13-18.

Loon Ang, K., D. Li and A.N. Nikoloski, 2017. The effectiveness of ion exchange resins in separating uranium and thorium from rare earth elements in acidic aqueous sulfate media. Part 1. Anionic and cationic resins, Hydrometallurgy, $174: 147-155$.

Loon Ang, K., D. Li and A.N. Nikoloski, 2018. The effectiveness of ion exchange resins in separating uranium and thorium from rare earth elements in acidic aqueous sulfate media. Part 2. Chelating resins, Minerals Engineering 123:8-15.

Mohapatra, P.K., D.S. Lakshmi, D. Mohan and V.K. Manchanda, 2006. Uranium pertraction across a PTFE flatsheet membrane containing Aliquat 336 as the carrier, Separation and Purification Technology 51, 24-30.

Orabi, A.H., E.M. El-Sheikh, W.H. Saleh, A.O. Youssef, M.Y. El-Kady and Z.M. Shalaby, 2015. Potentiality of uranium adsorption from wet phosphoric acid using amine-impregnated cellulose, Journal of Radiation Research and Applied Sciences. http://dx.doi.org/10.1016/j.jrras.2015.12.003.

Shakir, K, 1980. Extraction of uranium(VI) from dilute phosphate solutions with neotridecanohydroxamic acid and amines, Hydrometallurgy, 5: 191-206.

Senol, A., 2014. Optimization of extractive removal of uranium(VI) from aqueous acidic solutions using commercial amines: Linear solvation energy relation based modeling, Separation and Purification Technology 131:35-49.

Solvent Extraction Principle and Practice (SEPP), 2004, $2^{\text {ed }}$, Marcel Dekker, New York..

Toker, Y., M. Eral, Ü. Hiçsönmez, 1998. Recovery of uranium from aqueous solutions by trioctylamine impregnated polyurethane foam, Analyst, 123 (51-53).

Yousef, L.A. and G.M. Saleh, 2014. Uranium (VI) removal from flood water using trioctyl amine (TOA), at aburusheid area, south eastern desert, Egypt, IOSR Journal of Applied Chemistry. 7, (7):05-14.

Xie, F., T. Zhamg, D. Dreisinger and F. Doyle, Miner. Eng., 2014, 56, 10. 